\title{
In-Hospital outcomes in acute coronary syndrome patients with concomitant severe chronic kidney disease undergoing percutaneous coronary intervention
}

\author{
Saadia Sattar ${ }^{1}$, Naseer Ahmed², Zohaib Akhter ${ }^{3}$, Saba Aijaz ${ }^{4}$, \\ Shakir Lakhani ${ }^{5}$, Rehan Malik ${ }^{6}$, Asad Pathan
}

\section{ABSTRACT}

Objective: To determine in-hospital mortality and major adverse cardiac events (MACE) in acute coronary syndrome (AMI) patients with underlying severe chronic kidney disease (CKD) undergoing percutaneous coronary intervention $(\mathrm{PCl})$.

Methods: We conducted a retrospective cohort study from June'2013-December'2017 at Tabba Heart Institute, Karachi. Data was drawn from institutes' database modeled after US National Cardiovascular data CathPCI registry. All AMI (STEMI: ST-elevation myocardial infarction and NSTEMI: non-ST-elevation myocardial infarction) patients undergoing $\mathrm{PCl}$ with creatinine clearance $<30 \mathrm{ml} / \mathrm{min}$ or ESRD on hemodialysis were included in the study.

Results: During 54 months study period, 160 severe CKD patients underwent $\mathrm{PCl}$. Mean age was $62.9 \pm 12.2$ years. Men were $61.9 \%$, hypertensive (81.3\%) and diabetic (63.8\%). Excluding dialysis patients, Creatinine clearance was $21.1 \pm 6.6 \mathrm{ml} / \mathrm{min} / 1.73 \mathrm{~m}^{2}$. STEMI were $46.9 \%$ and $61.9 \%$ were Killip I. Mean SYNTAX score was 16.6 \pm 7.3. MACE occurred in $32.5 \%$ patients, of which $6(11.5 \%)$ had new hemodialysis and mortality: $17.5 \%$ were deceased. MACE predictor were cardiogenic shock (OR: $2.81,95 \% \mathrm{Cl}: 1.17-6.74$ ) and prior heart failure (OR: 6.84, 95\% Cl: 1.39-33.74), Predictor of mortality was cardiogenic shock or cardiac arrest (OR: 7.90 , 95\% Cl: 2.95-21.17).

Conclusion: Severe CKD patients undergoing $\mathrm{PCl}$ for $\mathrm{AMI}$ have drastically poor outcomes therefore individualization and patient-centric care management is mandatory.

KEYWORDS: Acute coronary syndrome, Renal Insufficiency, Percutaneous Coronary Intervention.

doi: https://doi.org/10.12669/pjms.35.2.276

How to cite this:

Sattar S, Ahmed N, Akhter Z, Aijaz S, Lakhani S, Malik R, et al. In-Hospital outcomes in acute coronary syndrome patients with concomitant severe chronic kidney disease undergoing percutaneous coronary intervention. Pak J Med Sci. 2019;35(2):291-297. doi: https://doi.org/10.12669/pjms.35.2.276

This is an Open Access article distributed under the terms of the Creative Commons Attribution License (http://creativecommons.org/licenses/by/3.0), which permits unrestricted use, distribution, and reproduction in any medium, provided the original work is properly cited.

\section{INTRODUCTION}

Chronic kidney disease (CKD) is a rapidly increasing public health concern and the mortality of severe CKD and end stage renal disease (ESRD) patients is very high as compared to the general population. ${ }^{1}$ Cardiovascular disease is the most common cause of death in these patients in the past, accounting for half of the mortality with an annual $18-20 \%$ death rate. ${ }^{2-6}$ CKD patients presenting with acute myocardial infarction (AMI) are a particularly high-risk group with data from the late 1990's showing $41 \%$ mortality at one year and up to $71 \%$ at five years. ${ }^{7}$ 
Patients with CKD also fare unfavorably during PCI with increased risk of bleeding complications, peri-procedural myocardial infarction, stent thrombosis and increased mortality. ${ }^{8}$ Renal function deterioration after PCI contributes further to a poorer prognosis in patients with preexisting CKD with a reported $6.8 \%$ in-hospital mortality ${ }^{9}$ and $>70 \%$ mortality over the period of two years. ${ }^{10}$ In the absence of outcome data of the additive benefits of revascularization in patients with AMI and severe CKD, clinicians may adopt a risk aversion approach and not recommend cardiac catheterization or revascularization. ${ }^{11}$

Clinical trials of cardiovascular therapies, in general exclude patients with severe CKD, and clinicians have to rely on retrospective, observational registries and meta-analysis to make patient care decisions. ${ }^{11}$ All these studies are published from North America, Europe or Japan; there is very limited data available from south Asia. Patients of these areas may have a different risk profile from Western, Caucasian and Oriental population and based on this we sought to determine the inhospital outcomes of AMI patients with severe CKD undergoing PCI.

\section{METHODS}

We conducted a retrospective cohort study from June 2013 through December 2017 at Tabba heart Institute Karachi, Pakistan. Data was retrieved from institute's patient database modeled according to standard United States National Cardiovascular Data Registry (NCDR) Cath-PCI registry. ${ }^{12}$ The registry collects data on patient and characteristics, clinical presentation, treatments, and outcomes associated with coronary angiography and/ or PCIs. There is a comprehensive data quality program, including both data quality report specifications for data capture and transmission and an auditing program. The data collected are exported in a standard format. The complete definitions of all variables were prospectively defined by a committee of the American College of Cardiology (ACC) and are available at the ACC NCDR Website.

For this study, we identified all AMI (STEMI: ST-elevation myocardial infarction and NSTEMI: non-ST-elevation myocardial infarction) patients of age $\geq 18$ years undergoing PCI having creatinine clearance $<30 \mathrm{ml} / \mathrm{min}$ or on hemodialysis. We excluded patients undergoing multiple PCI procedures during a single hospitalization. Approval from Tabba Heart Institute Ethics Review
Committee was obtained for the conduct of the study. Informed consent was taken from all patients at the time of admission for research purposed while maintaining confidentiality.

Study outcomes: It included in-hospital mortality and in-hospital major adverse cardiac events (MACE). In-hospital mortality was defined as mortality due to any cause post PCI. In-hospital MACE included heart failure, cerebrovascular accident/stroke, bleeding event within 72 hours, myocardial infarction and new need of hemodialysis.

Operational definition: Estimated glomerular filtration rate (eGFR; $\mathrm{ml} / \mathrm{min} / 1.73 \mathrm{~m}^{2}$ ) using initial serum creatinine of the patient was calculated by modification of diet in renal disease (MDRD) formula: eGFR $=186 \times$ Serum Cr-1.154 $x$ age-0.203 x 1.212 (if patient is black) x 0.742 (if female). ${ }^{13}$ Dialysis patients are considered as end stage renal disease (ESRD) and their creatinine clearance data was not included in the creatinine clearance calculation in our study population. All AMI patients (STEMI/NSTEMI) were included. STEMI or their equivalents were characterized by the presence of: a. symptoms suggestive of acute coronary ischemia. $b$. ECG evidence of STEMI: New or presumed new ST-segment elevation or new left bundle branch block with the cut-off points: $\geq 0.2 \mathrm{mV}$ in men or $\geq 0.15 \mathrm{mV}$ in women in leads V2-V3 and/or $\geq 0.1 \mathrm{mV}$ in other leads or true posterior infarcts. Left bundle branch block (LBBB) refers to new or presumed new LBBB on the initial ECG. NSTEMIs were characterized by the presence of: a. symptoms suggestive of acute coronary ischemia. b. Cardiac biomarkers (Troponin I) exceeding the diagnostic criteria cutoffs of Tabba Heart Institute's laboratory parameters with a clinical presentation which is consistent or suggestive of ischemia. c. ECG changes not meeting STEMI criteria. Heart failure was defined as unusual dyspnea on light exertion or recurrent dyspnea occurring in the supine position or fluid retention or the description of rales or jugular venous distension or pulmonary edema on physical exam; or pulmonary congestion on chest x-ray. Cerebrovascular accident was documented by a loss of neurological function caused by an ischemic or hemorrhagic event with residual symptoms lasting at least 24 hours after onset or leading to death. MI was defined as repeat symptoms of coronary ischemia with new ECG change. Biomarkers were not routinely checked after PCI and are only done in patients 
Table-I: Demographic, clinical, angiographic and procedural characteristics.

\begin{tabular}{|c|c|c|c|c|}
\hline \multirow[b]{2}{*}{ Characteristics } & \multicolumn{3}{|c|}{ In-hospital Event } & \multirow[b]{2}{*}{ p-value } \\
\hline & $\begin{array}{c}\text { Total } \\
(n=160)\end{array}$ & $\begin{array}{c}\text { Alive } \\
(n=132)\end{array}$ & $\begin{array}{c}\text { Deceased } \\
(n=28)\end{array}$ & \\
\hline \multicolumn{5}{|c|}{ Demographic and clinical characteristics } \\
\hline Age (years)* & $62.9 \pm 12.2$ & $62.9 \pm 11.7$ & $63.3 \pm 14.6$ & NS \\
\hline Male & 99 (61.9) & $78(59.1)$ & $21(75.0)$ & 0.12 \\
\hline $\begin{array}{l}\text { Diabetes mellitus } \\
\text { Insulin treatment }\end{array}$ & $\begin{array}{c}102(63.8) \\
46(46.0)\end{array}$ & $\begin{array}{l}84(63.6) \\
42(51.2)\end{array}$ & $\begin{array}{l}18(64.3) \\
4(22.2)\end{array}$ & $\begin{array}{c}\text { NS } \\
<0.001^{\#}\end{array}$ \\
\hline Hypertension & $130(81.3)$ & $114(86.4)$ & $16(57.1)$ & $<0.001$ \\
\hline Dyslipidemia & $56(35.0)$ & $52(39.4)$ & $4(14.3)$ & $0.01^{\#}$ \\
\hline Smokers & $21(13.1)$ & $18(13.6)$ & $3(10.7)$ & NS $S^{\#}$ \\
\hline Prior revascularization & $37(23.1)$ & $34(25.8)$ & $3(10.7)$ & 0.08 \\
\hline Prior known CAD & $46(28.7)$ & $42(31.8)$ & $4(14.3)$ & $0.06^{\#}$ \\
\hline Family history of premature CAD & $28(17.5)$ & $24(18.2)$ & $4(14.3)$ & $0 . \mathrm{NS}^{*}$ \\
\hline Cardiac arrest at arrival & $13(8.1)$ & $7(5.3)$ & $6(21.4)$ & $0.005^{\#}$ \\
\hline In-hospital stay (days)* & $5.5 \pm 3.7$ & $5.8 \pm 3.6$ & $4.2 \pm 3.8$ & 0.02 \\
\hline $\begin{array}{l}\text { Killip class on presentation } \\
\text { I } \\
\text { II } \\
\text { III } \\
\text { IV }\end{array}$ & $\begin{array}{l}99(61.9) \\
10(6.3) \\
28(17.5) \\
23(14.4)\end{array}$ & $\begin{array}{c}88(66.7) \\
8(6.1) \\
26(19.7) \\
10(7.6)\end{array}$ & $\begin{aligned} 11 & (39.3) \\
2 & (7.1) \\
2 & (7.1) \\
13 & (46.4)\end{aligned}$ & $<0.001^{\#}$ \\
\hline Initial Creatinine (mg/dl) & $3.4 \pm 1.9$ & $3.4 \pm 2.1$ & $3.0 \pm 0.8$ & 0.27 \\
\hline $\mathrm{eGFR}\left(\mathrm{ml} / \mathrm{min} / \mathrm{m}^{2}\right)$ & $21.1 \pm 6.6$ & $20.8 \pm 6.7$ & $22.7 \pm 5.9$ & 0.18 \\
\hline \multicolumn{5}{|c|}{ Angiographic and Procedural Characteristics } \\
\hline Pre PCI LVEF $(\%)^{*}$ & $40.6 \pm 10.6$ & $41.5 \pm 10.4$ & $34.2 \pm 9.9$ & 0.005 \\
\hline $\begin{array}{l}\text { Significant blockage } \\
\text { Left main disease } \\
\text { Multi vessel disease } \\
\text { Single vessel disease }\end{array}$ & $\begin{array}{c}5(3.1) \\
58(43.9) \\
97(60.6)\end{array}$ & $\begin{array}{c}5(3.2) \\
49(37.1) \\
79(59.7)\end{array}$ & $\begin{array}{c}1(10.7) \\
9(32.1) \\
18(64.3)\end{array}$ & $\mathrm{NS}^{\#}$ \\
\hline SYNTAX score* & $16.6 \pm 7.3$ & $16.0 \pm 7.4$ & $21.7 \pm 4.7$ & 0.07 \\
\hline $\begin{array}{l}\text { SYNTAX score risk categories } \\
\text { Low } \\
\text { Intermediate } \\
\text { High } \\
\text { Total (available) }\end{array}$ & $\begin{array}{c}45(83.3) \\
7(12.9) \\
2(3.7) \\
54(100)\end{array}$ & $\begin{array}{l}41(85.4) \\
5(10.4) \\
2(4.2) \\
48(100)\end{array}$ & $\begin{array}{l}4(66.7) \\
2(33.3) \\
0(0.0) \\
6(100)\end{array}$ & NS \\
\hline PCI treated vessel 1 & $108(67.5)$ & $87(65.9)$ & $21(75.0)$ & NS \\
\hline On hemodialysis & $21(13.3)$ & $18(13.6)$ & $3(10.7)$ & NS \\
\hline $\begin{array}{l}\text { PCI Indication } \\
\text { STEMI } \\
\text {-within } 24 \text { hours } \\
\text { NSTEMI }\end{array}$ & $\begin{array}{l}75(46.9) \\
60(37.5) \\
85(53.1)\end{array}$ & $\begin{array}{l}54(40.9) \\
43(32.6) \\
78(59.1)\end{array}$ & $\begin{array}{c}21(75.0) \\
17(60.7) \\
7(25.0)\end{array}$ & $0.001^{\$}$ \\
\hline Contrast volume (ml) & $111.3 \pm 78.1$ & $107.8 \pm 74.2$ & $128.4 \pm 94.4$ & 0.23 \\
\hline Shock at start of PCI & $17(10.6)$ & $6(4.6)$ & $11(39.3)$ & $<0.001$ \\
\hline Post procedure TIMI 3 flow & $156(97.5)$ & $132(100)$ & $24(85.7)$ & 0.001 \\
\hline Acute kidney injury & $57(35.6)$ & $46(34.9)$ & $11(39.3)$ & NS \\
\hline
\end{tabular}

${ }^{*}$ mean \pm SD "Fisher's exact test. ${ }^{\$}$ p-values between STEMI and NSTEMI. 
with suggestion of repeat ischemia. Bleeding event within 72 hours was defined as hemoglobin drop of $>3 \mathrm{~g} / \mathrm{dL}$ or transfusion of whole blood or packed red blood cells or procedural intervention/ surgery at the bleeding site to reverse/stop or correct the bleeding (such as surgical closures/ exploration of the arteriotomy site, balloon angioplasty to seal an arterial tear, endoscopy with cautery of a GI bleed). New hemodialysis; was defined as nonhemodialysis dependent patient requiring hemodialysis due to acute or worsening renal failure. Multi vessel disease was defined as significant blockage in more than one of the major coronary artery.

Statistical Plan: Results are presented as mean \pm SD for continuous variables and frequency with percentages for categorical variables. Continuous data were compared by means of Student's $t$ test; proportions by Chi-square test. Stepwise multivariable logistic model was developed for clinically relevant variables, to identify risk factors of in-hospital mortality and in-hospital MACE adjusting for CKD. Results are presented as odds ratios (ORs) with 95\% CIs. p-value <0.05 was considered statistically significant.

\section{RESULTS}

Study population and demographic characteristics: During the 54 months study period, a total of 7133 patients underwent PCI of which 160 $(2.2 \%)$ patients met the inclusion criteria of AMI presentation and underlying severe CKD. Patients already on hemodialysis were $13.1 \%$. Among the study patients, mean age was $62.9 \pm 12.2$ years, majority were men (61.9\%) (Table-I). Hypertension was present in $81.3 \%$, dyslipidemia in $35.0 \%$, diabetes in $63.8 \%$ and $13.1 \%$ of the patients were smokers. Prior history of revascularization with either PCI or CABG was present in $23.1 \%$ of the patients. Initial Creatinine was mean of $3.4 \pm 1.9$ $\mathrm{mg} / \mathrm{dl}$ and Creatinine clearance was $21.1 \pm 6.6 \mathrm{ml} /$ $\mathrm{min} / 1.73 \mathrm{~m}^{2}$.

Clinical presentation: A total of $46.9 \%$ patients' presented with STEMI and $53.1 \%$ patients with NSTEMI. Majority of the patients presented with Killip I (61.9\%). Cardiac arrest before PCI occurred $8.1 \%$ and $14 \%$ had cardiogenic shock on presentation Angiographic and procedural characteristics: Mean ejection fraction was $40.6 \% \pm 10.6$ and one third of the patients had ejection fraction $<35 \%$. Severe left main artery or multi vessel disease was present in $47 \% . S Y N T A X$ score was available for 54 patients
[Alive: 48 (36.4\%), dead: 6 (21.4\%)]. Mean SYNTAX score was 16.6 \pm 7.3 (Alive: $16.0 \pm 7.4$, dead: $21.7 \pm 4.7$ ). Single vessel PCI was done in $67.5 \%$ and post procedure TIMI 3 flow was achieved in $97.5 \%$ of the patients.

Post procedural event: In-hospital mortality was 17.5\% (STEMI: 28.0\%, NSTEMI: 8.2\%). Deceased patients were more likely to have cardiac arrest $(21.4 \%$ vs. $5.3 \%)$, KILLIP IV on presentation $(46.4 \%$ vs. $7.6 \%)$, slightly higher SYNTAX score $(21.7 \pm 4.7$ vs. $16.0 \pm 7.4)$, STEMI presentation $(75.0 \%$ vs. $40.9 \%)$ and TIMI flow $<3$ (85.7\% vs. $100 \%)$ (all p<0.05). Post procedure events were more likely to occur in deceased patients (Fig.1). A total of 52 (32.5\%) patients had one of the major adverse cardiac events including death. Mean hospital stay was $5.5 \pm 3.7$ days.

Predictors of In-hospital mortality and MACE: In multivariate analysis, MACE was more likely to occur in patients having cardiogenic shock (OR: 2.81, 95\%CI: 1.17-6.74, p-value: 0.02 ) and prior heart failure (OR: 6.84, 95\% CI: 1.39-33.74, p-value: 0.02) (Table-II). However, predictor of in-hospital mortality was cardiogenic shock or cardiac arrest (OR: 7.90, 95\%CI: 2.95-21.17, p-value: <0.001).

\section{DISCUSSION}

In this study, we looked at the in-hospital outcomes in 160 patients with AMI and severe CKD who underwent PCI. We observed that these patients had multiple co-morbidities, frequent cardiac arrest and cardiogenic shock at presentation. They usually have a prolonged hospital stay, worsening of renal function in a third of patients, frequently complicated with adverse events and high in-patient mortality of $17.5 \%$. Cardiogenic shock or prior heart failure predicted in-hospital adverse events.

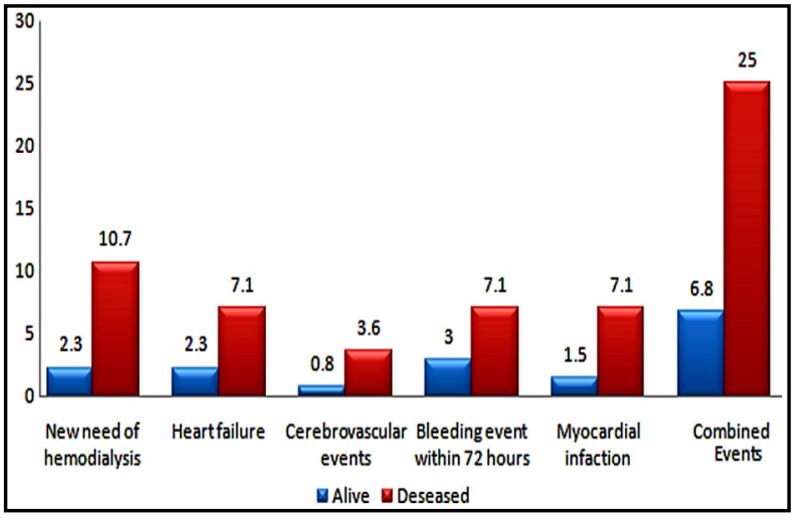

Fig.1: Post procedural events. 
Table-II: Predictors of in-hospital mortality and MACE $(n=160)$.

\begin{tabular}{|c|c|c|c|c|c|c|c|c|}
\hline \multirow{4}{*}{ Variable } & \multicolumn{8}{|c|}{ Multivariate models } \\
\hline & \multicolumn{4}{|c|}{ In-hospital mortality } & \multicolumn{4}{|c|}{ In-hospital MACE } \\
\hline & \multirow{2}{*}{$O R$} & \multirow{2}{*}{ p-value } & \multicolumn{2}{|c|}{$95 \% C I$} & \multirow{2}{*}{$O R$} & \multirow{2}{*}{$p$-value } & \multicolumn{2}{|c|}{$95 \% C I$} \\
\hline & & & Lower & Upper & & & Lower & Upper \\
\hline Cardiogenic shock or cardiac arrest & 7.90 & $<0.001$ & 2.95 & 21.17 & 2.81 & 0.02 & 1.17 & 6.74 \\
\hline Prior heart failure & - & - & - & - & 6.84 & 0.02 & 1.39 & 33.74 \\
\hline
\end{tabular}

Cardiovascular diseases are the leading cause of death in patients with severe CKD or ESRD. ${ }^{14}$ Renal dysfunction was shown in the HOPE trial to be a marker of increased cardiovascular risk and CKD is now considered a CHD equivalent. ${ }^{15}$ Majority of patients already have obstructive CHD at the time of initiation of dialysis and there is usually presence of multi-vessel disease with calcified, diffuse involvement. ${ }^{16}$ Patients with worsening degree of CKD have increasing cardiovascular events with a very high risk associated with ESRD.$^{17}$ In addition to an increased burden of traditional cardiovascular risk factors, presence of non-traditional risk factors such as anemia and a superimposed amplified pro-inflammatory state mediate the enhanced coronary and systemic burden of atherosclerosis. ${ }^{18}$ An alteration in calcium and phosphate metabolism present in renal dysfunction is associated with intimal calcium deposition in CKD and medial calcification in the coronary arteries with ESRD. ${ }^{19}$ There is marked endothelial dysfunction, altered coronary perfusion and along with increased atherosclerosis, leads to increased cardiovascular mortality. Coronary revascularization with PCI or surgery is challenging in these patients due to the presence of multiple co-morbidities, diffusely diseased and calcified coronary arteries, aortic and systemic vascular disease; there is associated high morbidity and mortality. ${ }^{20}$

The mortality rate in our study for AMI patients with underlying severe CKD is very high at $17.5 \%$ and patients mostly had low SYNTAX score suggesting less complex coronary anatomy. At the same time in half of the patients, index hospitalization was for STEMI presentation; most of whom (31\%) underwent emergency PCI within 24 hours of symptom onset. These patients have a higher risk of death and therefore an unfavorable influence on early survival. In a study from the late 1990's, Herzog et al showed that in ESRD patients, the 2-year mortality after myocardial infarction was $74 \% .{ }^{21}$ Results after revascularization in CKD patients are more limited. In the study from the European registry by Möckel et al, STEMI patients had a higher risk of death with an OR of $2.16 .{ }^{22}$ In the study by Shroff et al the patients with AMI and multi-vessel disease derived greater benefit from CABG as compared to PCI with DES; HR 0.92 for predicting mortality in DES versus CABG. ${ }^{23}$ However, patients presenting with acute STEMI should still be treated with PCI because of a shorter presentation to treatment time.

The overall rate of adverse events is very high in our study consistent with the high-risk population. ${ }^{10}$ Over $30 \%$ of patients had one of the adverse events; with death, heart failure, bleeding and dialysis being the more common. This highlights the importance of multiple risk reduction measures that are recommended in the guidelines and best practices: accurate measurement of creatinine clearance in all patients, adjustment of anticoagulants based on creatinine clearance and weight, careful assessment of volume status to avoid both volume depletion and volume overload in order to reduce heart failure and acute kidney injury, preference for radial artery access and minimizing iodinated contrast utilization with strict attention to safe contrast volume. ${ }^{24,25}$ The risk of contrast nephropathy can be further reduced by staging complex procedures and using intravascular ultrasound or optical coherence tomography guidance instead of fluoroscopy. ${ }^{26}$

We only found cardiogenic shock at presentation and a history of heart failure as predictors of inhospital adverse events. This is probably explained by the small sample size. Previous studies have also found cardiogenic shock to be a strong predictor 
of in hospital death with $40-50 \%$ mortality in most studies. ${ }^{27}$ Most randomized trials excluded patients with severe CKD, and even in the observational registries, patients with the combination of severe CKD and AMI are poorly represented. ${ }^{11}$ This clearly represents a dilemma to the treating cardiologist, as generalizing data from trials where such patients were excluded can be misleading. These patients have a poor outcome with medical therapy which may imply use of more aggressive approaches. However, based on their advanced multiple comorbidities, worse clinical presentation and complex medical problems, there is a much higher risk of adverse outcome; unfavorably affecting the risk benefit ratio of coronary revascularization procedures. This further stresses the importance of individualization and patient-centric care management.

Limitations of the study: We acknowledge that this is the single-center experience represented through this data. This may limit the generalizability of conclusions. The sample size of the study was small which may lead to lack of significant predictors. There is also a possibility that predictors of in-hospital mortality or inhospital mace (study outcomes) could reflect measured or unmeasured co-morbidities in patients with advance CKD.

\section{CONCLUSION}

Cardiovascular diseases are the most frequent cause of mortality in patients with severe CKD and ESRD. Patients with severe CKD and associated AMI have historically a very poor outcome. These patients are not included in randomized trials and the observational registries have reported very limited or no data from South Asia.We observed that patients with severe CKD and AMI have multiple co-morbidities, frequent cardiac arrest and cardiogenic shock at presentation. They usually have a prolonged hospital stay, worsening of renal function in a third of patients, frequently complicated with adverse events and high inpatient mortality. There is need for individualization and patientcentric care management.

Disclaimer: None.

Conflict of Interest: None.

Source of Funding: None.

Grant Support E Financial Disclosures: None.

\section{REFERENCES}

1. Go AS, Chertow GM, Fan D, McCulloch CE,Hsu C-y. Chronic kidney disease and the risks of death, cardiovascular events, and hospitalization. N Engl J Med. 2004;351(13):1296-1305. doi: 10.1056/NEJMoa041031.

2. Lindner A, Charra B, Sherrard DJ, Scribner BH. Accelerated atherosclerosis in prolonged maintenance hemodialysis. N Engl J Med. 1974;290(13):697-701. doi: 10.1056/ NEJM197403282901301.

3. Gokal R, King J, Bogle S, Marsh F, Oliver D, Jakubowski $\mathrm{C}$, et al. Outcome in patients on continuous ambulatory peritoneal dialysis and haemodialysis: 4-year analysis of a prospective multicentre study. Lancet. 1987;330(8568):11051109. doi: 10.1016/S0140-6736(87)91544-3.

4. Kasiske BL, Guijarro C, Massy ZA, Wiederkehr MR, Ma JZ. Cardiovascular disease after renal transplantation. J Am Soc Nephrol. 1996;7(1):158-165.

5. Rinehart AL, Herzog CA, Collins AJ, Flack JM, Ma JZ, Opsahl JA. A comparison of coronary angioplasty and coronary artery bypass grafting outcomes in chronic dialysis patients. Am J Kidney Dis. 1995;25(2):281-290. doi: 10.1016/0272-6386(95)90010-1.

6. Hellerstedt WL, Johnson WJ, Ascher N, Kjellstrand CM, Knutson R, Shapiro FL, et al. Survival Rates of 2,728 Patients With End-Stage Renal Disease ${ }^{* *}$ A complete 80 -page survival study report, including survival by treatment modality, is available by writing to the Renal Network Coordinating Council of the Upper Midwest, 2331 University Ave., S.E., Suite 101, Minneapolis, MN 55414. Mayo Clin Proc. 1984;59(11):776-783. doi: 10.1016/S0025-6196(12)65589-X.

7. Herzog CA, Ma JZ, Collins AJ. Poor long-term survival after acute myocardial infarction among patients on long-term dialysis. N Engl J Med. 1998;339(12):799-805. doi: 10.1056/ NEJM199809173391203.

8. Latif F, Kleiman NS, Cohen DJ, Pencina MJ, Yen C-H, Cutlip DE, et al. In-hospital and 1-year outcomes among percutaneous coronary intervention patients with chronic kidney disease in the era of drug-eluting stents: a report from the EVENT (Evaluation of Drug Eluting Stents and Ischemic Events) registry. JACC Cardiovasc Interv. 2009;2(1):37-45. doi: 10.1016/j.jcin.2008.06.012.

9. Gruberg L, Dangas G, Mehran R, Mintz GS, Kent KM, Pichard AD, et al. Clinical outcome following percutaneous coronary interventions in patients with chronic renal failure. Catheter Cardiovasc Interv. 2002;55(1):66-72. doi: 10.1002/ ccd.10103.

10. Best PJ, Lennon R, Ting HH, Bell MR, Rihal CS, Holmes DR, et al. The impact of renal insufficiency on clinical outcomes in patients undergoing percutaneous coronary interventions. J Am Coll Cardiol. 2002;39(7):1113-1119. doi: 10.1016/S07351097(02)01745-X

11. Charytan D, Kuntz R. The exclusion of patients with chronic kidney disease from clinical trials in coronary artery disease. Kidney Int. 2006;70(11):2021-2030. doi: 10.1038/ sj.ki.5001934.

12. Moussa I, Hermann A, Messenger JC, Dehmer GJ, Weaver WD, Rumsfeld JS, et al. The NCDR CathPCI Registry: a US national perspective on care and outcomes for percutaneous coronary intervention. Heart. 2013:heartjnl-2012-303379. doi: 10.1136/heartjnl-2012-303379.

13. Lamb EJ, Webb MC, O'Riordan SE. Using the modification of diet in renal disease (MDRD) and Cockcroft and Gault equations to estimate glomerular filtration rate (GFR) in older people. Age Ageing. 2007;36(6):689-692. doi: 10.1093/ ageing/afm121. 
14. Webster AC, Nagler EV, Morton RL, Masson P. Chronic kidney disease. Lancet. 2017;389(10075):1238-52.doi: 10.1016/S0140-6736(16)32064-5.

15. Mann JF, Gerstein HC, Pogue J, Bosch J, Yusuf S. Renal insufficiency as a predictor of cardiovascular outcomes and the impact of ramipril: the HOPE randomized trial. Ann Intern Med. 2001;134(8):629-636.

16. Chonchol M, Whittle J, Desbien A, Orner MB, Petersen LA, Kressin NR. Chronic kidney disease is associated with angiographic coronary artery disease. Am J Nephrol. 2008;28(2):354-360. doi: 10.1159/000111829.

17. Keeley EC, Kadakia R, Soman S, Borzak S, McCullough PA. Analysis of long-term survival after revascularization in patients with chronic kidney disease presenting with acute coronary syndromes. Am J Cardiol. 2003;92(5):509-514. doi: 10.1016/S0002-9149(03)00716-1.

18. Muntner P, Hamm LL, Kusek JW, Chen J, Whelton PK, He J. The prevalence of nontraditional risk factors for coronary heart disease in patients with chronic kidney disease. Ann Intern Med. 2004;140(1):9-17.

19. London GM, Guerin AP, Marchais SJ, Metivier F, Pannier $\mathrm{B}$, Adda $\mathrm{H}$. Arterial media calcification in end-stage renal disease: impact on all-cause and cardiovascular mortality. Nephrol Dial Transplant. 2003;18(9):1731-1740.doi: 10.1093/ ndt/gfg414.

20. Ota T, Umeda H, Yokota S, Miyata S, Takamura A, Sugino S, et al. Relationship between severity of renal impairment and 2-year outcomes after sirolimus-eluting stent implantation. Am Heart J. 2009;158(1):92-98.doi: 10.1016/j.ahj.2009.04.013.

21. Herzog CA. Acute myocardial infarction in patients with end-stage renal disease. Kidney Int. 1999;56:S130-S133.doi: 10.1046/j.1523-1755.1999.07132.x.

22. Möckel M, Searle J, Baberg HT, Dirschedl P, Levenson B, Malzahn J, et al. Revascularisation of patients with endstage renal disease on chronic haemodialysis: bypass surgery versus $\mathrm{PCI}-$ analysis of routine statutory health insurance data. Open Heart. 2016;3(2):e000464. doi: 10.1136/ openhrt-2016-000464.

23. Shroff GR, Solid CA, Herzog CA. Impact of acute coronary syndromes on survival of dialysis patients following surgical or percutaneous coronary revascularization in the United States. Eur Heart J Acute Cardiovasc Care. 2016;5(3):205-213. doi: 10.1177\%2F2048872615574106.

24. Members ATF, Kolh P, Windecker S, Alfonso F, Collet J-P, Cremer J, et al. 2014 ESC/EACTS guidelines on myocardial revascularization: the task force on myocardial revascularization of the European Society of Cardiology (ESC) and the European Association for Cardio-Thoracic Surgery (EACTS) developed with the special contribution of the European Association of Percutaneous Cardiovascular Interventions (EAPCI). Eur J Cardiothorac Surg. 2014;46(4):517-592. doi: 10.1093/ejcts/ezu366.
25. ERBP: a-hwgo, Fliser D, Laville $M$, Covic A, Fouque D, Vanholder R, et al. A European Renal Best Practice (ERBP) position statement on the Kidney Disease Improving Global Outcomes (KDIGO) clinical practice guidelines on acute kidney injury: part 1: definitions, conservative management and contrast-induced nephropathy. Nephrol Dial Transplant. 2012;27(12):4263-4272. doi: 10.1093/ndt/ gfs375.

26. Mariani J, Guedes C, Soares P, Zalc S, Campos CM, Lopes AC, et al. Intravascular ultrasound guidance to minimize the use of iodine contrast in percutaneous coronary intervention: the MOZART (Minimizing cOntrast utiliZation With IVUS Guidance in coRonary angioplasTy) randomized controlled trial. JACC Cardiovasc Interv. 2014;7(11):1287-1293. doi: 10.1016/j.jcin.2014.05.024.

27. De Luca L, Olivari Z, Farina A, Gonzini L, Lucci D, Di Chiara A, et al. Temporal trends in the epidemiology, management, and outcome of patients with cardiogenic shock complicating acute coronary syndromes. Eur J Heart Fail. 2015;17(11):1124-1132. doi: 10.1002/ejhf.339.

\section{Authors Contribution}

SS \& ZA: Conceived, designed and did statistical analysis \& writing of manuscript.

RM, NA, \& SL: Did data collection, data editing and editing of manuscript.

AP \& SA: Did clinical interpretation of data, review and final approval of manuscript.

Authors:

1. Saadia Sattar, M.Sc Epi-Bio.

Research Consultant, Department of Clinical Research, Cardiology,

2. Naseer Ahmed, MBBS Cardiology Fellow, Department of Cardiology,

3. Zohaib Akhter, M.Sc Epi-Bio. Research Consultant, Department of Clinical Research, Cardiology,

4. Saba Aijaz, FCPS. Consultant Cardiologist, Cardiology,

5. Shakir Lakhani, FCPS Consultant Cardiologist, Cardiology,

6. Rehan Malik, Research Officer, Department of Cardiology,

7. Asad Pathan, FACC Consultant Cardiologist, Cardiology,

1-7: Tabba Heart Institute, Karachi, Pakistan. 